\title{
A STUDY ON THE PREVALENCE AND SEVERITY OF POSSIBLE DRUG-DRUG INTERACTIONS IN PEDIATRICS DEPARTMENT AT AN INDIAN TERTIARY CARE TEACHING HOSPITAL
}

\author{
RAMAM SRIPADA ${ }^{1}$, S. V. SURESH KUMAR ${ }^{2}$, N. DEVANNA ${ }^{3}$, KANDULA RAVINDRA REDDY ${ }^{4}$ \\ ${ }^{1}$ Research Scholar, CES College of Pharmacy, Kurnool, Andhra Pradesh, India, ${ }^{2}$ Department of Pharmacognosy, CES College of Pharmacy, \\ Kurnool, Andhra Pradesh, India, ${ }^{3}$ Director-OTPRI, JNTUA, Anantapur, ${ }^{4}$ Professor and Principal, PRRM College of Pharmacy, Kadapa, \\ Andhra Pradesh, India \\ Email: sureshsolleti@gmail.com
}

Received: 07 May 2018 Revised and Accepted: 05 Jun 2018

\begin{abstract}
Objective: To study the prevalence and severity of possible drug-drug interactions in the department of pediatrics.

Methods: Case records of the in-patients of the pediatrics department from the medical records department were included and the records of the ambulatory patients were excluded from the study. All the collected cases were subjected to check for the drug-drug interactions by using the software micromedex 2.0 and the interactions were categorized based on the severity into minor, moderate and major.

Results: A total of 142 cases were screened for possible drug-drug interactions (DDIs) and among them 76 cases were observed to be with possible DDIs. The prevalence was found to be 53.5\% in this study. Majority of the cases with possible DDIs were observed to be in females. Results of the age wise categorization revealed that majority of the possible DDIS were observed in children (2-12 y) followed by the infants (1 mo- 2 y). The drug combinations amikacin+ampicillin, paracetamol+phenytoin and ofloxacin+ondansetron were found to be the frequently observed possible DDIs of minor, moderate and major severities respectively.
\end{abstract}

Conclusion: Majority of the possible DDIs were of moderate severity followed by major. Clinical pharmacists should take the responsibility in assisting the pediatricians for screening the possible DDIs in the prescriptions there by preventing them and providing a better pharmaceutical care for the pediatric population.

Keywords: Drug-drug interactions, Micromedex, Pediatrics, Polypharmacy

(c) 2018 The Authors. Published by Innovare Academic Sciences Pvt Ltd. This is an open access article under the CC BY license (http://creativecommons.org/licenses/by/4.0/) DOI: http://dx.doi.org/10.22159/ijpps.2018v10i7.27183

\section{INTRODUCTION}

Drug-drug interactions (DDIs) can be defined as the modification of the pharmacological or clinical response to a drug due to the concomitant administration of another drug [1]. Age, polypharmacy, concurrent disease conditions are some of the risk factors associated with DDIs. The prevalence of DDIs in various countries was reported in between $19.3-88.8 \%$. In terms of a rationale prescription, DDIs have become a major clinical concern and they may tend to cause adverse events majorly in the hospitalized patients where we used to observe the polypharmacy in their prescriptions [2-10]. Careful detection and monitoring of DDIs can enhance the quality and safety of drug therapy. DDIs increase the duration of hospital stay and even the health care costs too [11-15]

DDIs have attained a great attention from the scientific, regulatory and healthcare communities globally. Majority of the studies investigated the possible DDIs in different specialties like general medicine, oncology, cardiology, pulmonology and psychiatry where the information is just restricted to the adult population [16-23]. Very few studies were performed in the pediatrics specialty and hence, in this study we made an attempt to study the prevalence and severity of possible drug-drug interactions in pediatrics specialty.

\section{MATERIALS AND METHODS}

The present study was a retrospective cross-sectional study, conducted at Konaseema Institute of Medical Sciences (KIMS),
Amalapuram, Andhra Pradesh, India. This study was approved by the institutional ethics committee (No: 97/2015). Case records of the in-patients of the pediatrics department from the medical records department were included and the records of the ambulatory patients were excluded from the study. All the collected cases were subjected to check for the drug-drug interactions by using the software micromedex 2.0 and the interactions were categorized based on the severity into minor, moderate and major $[24,25]$.

\section{Statistical analysis}

SPSS 21.0 was used to perform the statistical analysis. Chi square test was performed and p-values were obtained at $95 \%$ confidence interval for finding the statistical significance $(\mathrm{p}<0.05)$.

\section{RESULTS}

Table 1 represents the gender wise categorization of the cases in the department of pediatrics included in the study. A total of 142 cases were screened for possible drug-drug interactions out of which 75 $(52.8 \%)$ were found to be males and $67(47.2 \%)$ were found to be females. Among the 142 cases which were screened for detecting the possible drug-drug interactions, about 76 cases were observed with possible drug-drug interactions and the prevalence was found to be 53.5\%. Among the 76 cases observed with possible drug-drug interactions, about $34(44.7 \%)$ were found to be males and 42 $(55.3 \%)$ were found to be females.

Table 1: Gender wise categorization of cases included in the study

\begin{tabular}{|c|c|c|c|c|c|}
\hline Gender & Cases observed with interactions (\%) & Cases observed without interactions (\%) & Total (\%) & $\chi 2$-value & p-value \\
\hline Male & $34(44.7)$ & $41(62.1)$ & $75(52.8)$ & 4.28 & $0.03^{*}$ \\
\hline Female & $42(55.3)$ & $25(37.9)$ & $67(47.2)$ & & \\
\hline Total & $76(100)$ & $66(100)$ & $142(100)$ & & \\
\hline
\end{tabular}

\footnotetext{
*indicates statistically significant
} 
Table 2 represents the age wise categorization of patients observed with possible drug-drug interactions. The patients in the age group 2-12 y (children) was observed to be with high a prevalence rate (72.3\%) followed by the age group 1 month-2years (infants) with a prevalence rate of $14.5 \%$.

Table 3 represents the categorization of patients observed with drug-drug interactions based on duration. Majority of the patients who were observed with possible drug-drug interactions were found to be stayed for 1-5 d (50\%).

Table 4 represents the categorization of prescriptions observed with drug-drug interactions based on polypharmacy in the pediatrics department. About 19 (25\%) prescriptions were observed to be with major polypharmacy, about 37 (48.7\%) prescriptions were observed to be with moderate polypharmacy and about $20(26.3 \%)$ prescriptions were observed to be with minor polypharmacy.

Table 5 and fig. 1 represents the severity of drug-drug interactions in the pediatrics department. A total of 136 possible drug-drug interactions were observed in this department out of which 21
(15.4\%) were of minor severity, 70 (51.5\%) were of moderate severity and $45(33.1 \%)$ were of major severity.

Table 6 represents the most frequently observed possible minor, moderate and major drug-drug interactions in the department of pediatrics.

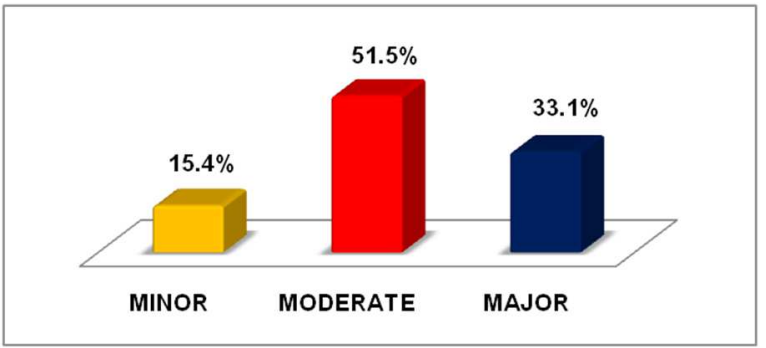

Fig. 1: Severity of the drug-drug interactions in the study

Table 2: Age wise categorization of patients observed with drug-drug interactions

\begin{tabular}{llll}
\hline Age group & Male (\%) & Female (\%) & \\
\hline Neonates (1 d-1 mo) & $2(5.9)$ & $3(7.1)$ & $5(6.6)$ \\
Infants (1 mo-2 y) & $4(11.8)$ & $7(16.7)$ & $11(14.5)$ \\
Children (2-12 y) & $25(73.5)$ & $30(71.4)$ & $55(72.3)$ \\
Adolescents (12-16 y) & $3(8.8)$ & $2(4.8)$ & $5(6.6)$ \\
Total & $34(100)$ & $42(100)$ & $76(100)$ \\
\hline
\end{tabular}

Table 3: Categorization of patients observed with DDIs based on duration of stay

\begin{tabular}{llll}
\hline Duration of stay (in days) & Male (\%) & Female (\%) & Total (\%) \\
\hline $1-5$ & $15(44.1)$ & $23(54.7)$ & $38(50)$ \\
$6-10$ & $14(41.2)$ & $15(35.7)$ & $29(38.3)$ \\
$11-15$ & $4(11.8)$ & $2(4.8)$ & $6(7.8)$ \\
$16-20$ & $1(2.9)$ & $2(4.8)$ & $3(3.9)$ \\
Total & $34(100)$ & $42(100)$ & $76(100)$ \\
\hline
\end{tabular}

Table 4: Categorization of prescriptions observed with DDIs based on polypharmacy

\begin{tabular}{lll}
\hline Type of polypharmacy & Male (\%) & Female (\%) \\
\hline Minor (3-5 drugs) & $8(23.5)$ & $12(28.6)$ \\
Moderate (6-8 drugs) & $17(50)$ & $20(47.6)$ \\
Major ( $\geq 9$ drugs) & $9(26.5)$ & $10(23.8)$ \\
Total & $34(100)$ & $42(100)$ \\
\hline
\end{tabular}

Table 5: Severity of the drug-drug interactions

\begin{tabular}{lllll}
\hline Severity & Male (\%) & Female (\%) & Total (\%) & p-value \\
\hline Minor & $7(11.5)$ & $14(18.7)$ & $21(15.4)$ & 4.83 \\
Moderate & $28(45.9)$ & $42(56)$ & $70(51.5)$ & \\
Major & $26(42.6)$ & $19(25.3)$ & $45(33.1)$ & \\
Total & $61(100)$ & $75(100)$ & $136(100)$ & \\
\hline
\end{tabular}

Table 6: Most frequently observed possible DDIs

\begin{tabular}{lll}
\hline Minor & Moderate & Major \\
\hline Amikacin+Ampicillin & Paracetamol+Phenytoin & Ofloxacin+Ondansetron \\
Amikacin+Piperacillin & Furosemide+Hydrocortisone & Metronidazole+Ondansetron \\
Carbamazepine+Clobazam & Ondansetron+Tramadol & Midazolam+Phenobarbital \\
\hline
\end{tabular}

\section{DISCUSSSION}

A total of 142 cases were screened for possible drug-drug interactions (DDIs) and among them 76 cases were observed to be with possible DDIs. The prevalence was found to be $53.5 \%$ in this study. Majority of the cases with possible DDIs were observed to be in females. Results of the age wise categorization revealed that majority of the possible DDIS were observed in children (2-12 y) followed by the infants (1 mo-2 y). Majority of the patients who were observed with possible DDIs were observed to be stay for duration of $1-5 \mathrm{~d}$ (50\%) followed by 6-10 d (38.3\%).

In this study, majority of the prescriptions were found to be with moderate polypharmacy followed by minor polypharmacy. The 
severity of the majority of the possible DDIs in this study was observed to be moderate. This result was found to be similar with the study done by Mohammad Ismail et al. [16] and Qorraj-Bytyqi et al. [25]. The drug combinations amikacin+ampicillin, paracetamol +phenytoin and ofloxacin+ondansetron were found to be the frequently observed possible DDIs of minor, moderate and major severities respectively.

\section{CONCLUSION}

In this study, the prevalence of possible DDIs was found to be $53.5 \%$. Polypharmacy was associated with the occurrence of possible DDIs and in this study majority of the possible DDIs were observed in the prescriptions with moderate polypharmacy. Majority of the possible DDIs were of moderate severity followed by major that indicates that there is a need for the screening of possible DDIs. Clinical pharmacists should take the responsibility in assisting the paediatricians for screening the possible DDIs in the prescriptions thereby preventing them and providing a better pharmaceutical care for the pediatric population.

\section{LIMITATION}

This study with a prospective type of approach along with the involvement of other health care professionals would show a significant impact in screening the clinically encountered drug-drug interactions for providing the better pharmaceutical care for the patients by the direct involvement of the clinical pharmacist.

\section{AUTHORS CONTRIBUTION}

All authors had equally contributed to the research work.

\section{CONFLICTS OF INTERESTS}

None

\section{REFERENCES}

1. El Samia, Mohamed SMA, Gad ZM, El-Nimr NA, Abdel Razek AAH. Prevalence and pattern of potential drug-drug interactions in the critical care units of a tertiary hospital in Alexandria, Egypt. Adv Pharmacoepidemiol Drug Saf 2013;2:1-6.

2. Edisa T, Nurka P, Lejla B, Fahir B. Prevalence of polypharmacy and drug interaction among hospitalized patients: opportunities and responsibilities in pharmaceutical care. Mat Soc Med 2012;24:68-72.

3. Bergman U, Wiholm BE. Drug-related problems causing admission to a medical clinic. Eur J Clin Pharmacol 1981;20:193-200.

4. Koh Y, Moldeen Kutty FB, Chuen LS. Drug-related problems in hospitalized patients on polypharmacy: the influence of age and gender. Ther Clin Risk Manag 2005;1:39-48.

5. Beijer HJM, De Blaey CJ. Hospitalisations caused by adverse drug reactions (ADR): A meta-analysis of observational studies. Pharm World Sci 2002;24:46-54.

6. Brennan TA, Leape LL, Laird NM. The incidence of adverse drug events and negligence in hospitalized patients: results of harvard medical practice study I. N Engl J Med 1991;324:370-6.

7. Classen DC, Pestotnik SL, Evans RS. Adverse drug events in hospitalized patients. Excess length of stay, extra costs and attributable mortality. JAMA 1997;277:301-6.

8. Reimche L, Forster AJ, van Walraven C. Incidence and contributors to potential drug-drug interactions in hospitalized patients. J Clin Pharmacol 2011;51:1043-50.
9. Straubhaar B, Krahenbuhl S, Schlienger RG. The prevalence of potential drug-drug interactions in patients with heart failure at hospital discharge. Drug Saf 2006;29:79-90.

10. Athira Jith, Chaithanya T Kumar, Joffey Sara Joy, Kavitha Samy P, Sambath Kumar R. A prospective study of drug-drug interactions and adverse drug reactions among stroke patients in a tertiary care hospital. Asian J Pharm Clin Res 2016;9 Suppl 3:100-4.

11. Qorraj Bytyqi H, Hoxha R, Krasniqi S, Bahtiri E, Kransiqi V. The incidence and clinical relevance of drug interactions in paediatrics. J Pharmacol Pharmacother 2012; 3:3047.

12. Tom Revzon C. Drug Interactions. Pediatr Rev 2006;27:315-7.

13. Puckett WH Jr, Visconti JA. An epidemiologic study of the clinical significance of drug-drug interactions in a private community hospital. Am J Hosp Pharm 1971;28:247-53.

14. Leape LL, Brennan TA, Laird N, Lawthers AG, Localio AR, Barnes BA, et al. The nature of adverse events in hospitalized patients. Results from the Harvard Medical Practice Study II. N Engl J Med 1991;324:377-84.

15. Tatro DS. Drug interaction facts. St. Louis: Facts and Comparison; 2004.

16. Mohammad Ismail, Zafar Iqbal, Muhammad I Khan, Arshad Javaid, Hassan Arsalan, Farhadullah, et al. Frequency, levels and predictors of potential drug-drug interactions in a paediatrics ward of a teaching hospital in Pakistan. Trop J Pharm Res 2013;12:401-6.

17. Ismail M, Iqbal Z, Khattak MB, Javaid A, Khan MI, Khan TM. Potential drug-drug interactions in cardiology ward of a teaching hospital. Healthmed 2012;6:1618-24.

18. Van Leeuwen RW, Swart EL, Boven E, Boom FA, Schuitenmaker MG, Hugtenburg JG. Potential drug interactions in cancer therapy: a prevalence study using an advanced screening method. Ann Oncol 2011;22:2334-41.

19. Ismail M, Iqbal Z, Khattak MB, Javaid A, Khan MI, Khan TM, et al. Potential drug-drug interactions in psychiatric ward of a tertiary care hospital: prevalence, levels and association with risk factors. Trop J Pharm Res 2012;11:289-96.

20. Mateti UV, Rajakannan T, Nekkanti H, Rajesh V, Mallaysamy SR, Ramachandran P. Drug-drug interactions in hospitalized cardiac patients. J Young Pharmacists 2011;3:329-33.

21. Reis AM, Cassiani SH. Prevalence of potential drug interactions in patients in an intensive care unit of a university hospital in Brazil. Clinics 2011;66:9-15.

22. Ismail M, Iqbal $Z$, Khattak MB, Javaid A, Khan TM. Prevalence, types and predictors of potential drug-drug interactions in pulmonology ward of a tertiary care hospital. Afr J Pharm Pharmacol 2011;5:1303-9.

23. Hoffmann W, Van Den Berg N, Thyrian JR, Fiss T. Frequency and determinants of potential drug-drug interactions in an elderly population receiving regular home visits by GPs-results of the home medication review in the AGnES-studies. Pharmacoepidemiol Drug Saf 2011;20:1311-8.

24. Ramam S, Suresh Kumar SV, Devanna N, Ravindra Reddy K. Prevalence and severity of possible drug-drug interactions in the inpatient department of internal medicine. Int J Pharm Clin Res 2016;8:1212-4.

25. Qorraj Bytyqi H, Hoxha R, Krasniqi S, Bahtiri E, Kransiqi V. The incidence and clinical relevance of drug interactions in paediatrics. J Pharmacol Pharmacother 2012;3:304-7. 